\title{
Castleman's Disease presenting as a pleural mass in the thoracic cavity
}

\author{
E. Sulu1, Özlem Makbule Akbay'1, Esra Akkutuk Öngel11, F. Aksoy², \\ G. Bektemur ${ }^{3}$, Huriye Berk Takir ${ }^{1}$, A. Yilmaz ${ }^{1}$
}

\begin{abstract}
Castleman's Disease presenting as a pleural mass in the thoracic cavity. E. Sulu, Özlem Makbule Akbay, Esra Akkutuk Öngel, F. Aksoy, G. Bektemur, Huriye Berk Takir, A. Yilmaz.

A 61-year-old non-smoking Turkish woman presented with chest pain for 10 months. Computed tomography of the chest revealed a solitary, relatively well circumscribed,
\end{abstract}

heterogeneous mass of $4 \times 6 \mathrm{~cm}$ diameter in left posteriorlateral hemithorax. On thoracotomy, an extraparanchymal mass destructing the ribs was determined. Mass excision and partial chest wall resection were performed. On histopathologic examination, this mass showed features of the hyaline vascular type of Castleman's Disease. Monaldi Arch Chest Dis 2012; 77: 3-4, 139-140.

Keywords: Castleman's Disease, Pleura, Hyaline vascular type, Surgery.

1 Sureyyapasa Chest Diseases and Thoracic Surgery Training and Investigation Hospital, Istanbul;

2 Department of Pulmonology, Department of Pathology, 3 Yavuz Sultan Selim Hospital, Department of Pulmonology, Istanbul, Tukey.

Correspondence: Associate Professor Adnan Ylmaz, Maltepe Altayçeşme Mah. Seri Sok. Yasamkent Sitesi, Manolya Blok Kat 6 Daire: 26 Istanbul,Turkey; e-mail: adnandr_63@yahoo.co.uk

Castleman's disease (CD) is a rare disorder that results in unregulated growth of lymphoid tissue (1). It was initially described by Castleman, in 1954 (2). CD can be found wherever lymph nodes are present (3). It has also been described in the extralymphatic tissues, including lung, muscle, pancreas, and larynx (4). CD of pleura is rare and only a few cases have been reported in the literature (1). We report a new case and review the literature.

\section{Case Report}

A 61-year-old non-smoking Turkish woman presented with chest pain for 10 months. Her past medical history was unremarkable. Chest radiograph showed heterogeneous density obliterating left costophrenic sinus (figure 1). Physical examination and laboratory findings were unremarkable. Computed tomography of the chest revealed a solitary, relatively well circumscribed, heterogeneous mass of $4 \times 6 \mathrm{~cm}$ diameter in left posterior-lateral hemithorax. This mass contained intralesional calcification and necrosis). Fiberoptic bronchoscopy examination showed normal appearance. CT-guided cutting needle biopsy was carried out but no diagnostic conclusion was obtained. Magnetic resonance imaging revealed $4 \times 6 \mathrm{~cm}$ sized mass having calcification and necrosis (figure 2). Left posterolateral thoracotomy was performed. On the thoracotomy, the ovoid mass was located on the parietal pleura, destructing left eighth and nineth ribs. The mass was completely resected and partial resection of eighth and nineth ribs was performed.
Macroscopically, the mass was measured to be $4 \mathrm{x}$ $6.5 \mathrm{~cm}$ in size, was pinkish-yellow in colour and ovoid-shaped. It had a rubbery consistency with fibrous bands. Microscopically, the lesion was composed of germinal follicles with hyalinised vessels surrounded by concentric layers of small lymphocytes and prominent interfolllicular vascular stroma (figure 3). The immunohistochemical examination revealed the following: positivity for Cluster Denomination (CD) 45 and CD20 in the follicle cells; positivity for CD3 in the interfollicular area; negativity for pancytokeratin in the all cells. The final diagnosis was the classic hyaline vascular type of Castleman's disease in the pleura. Four

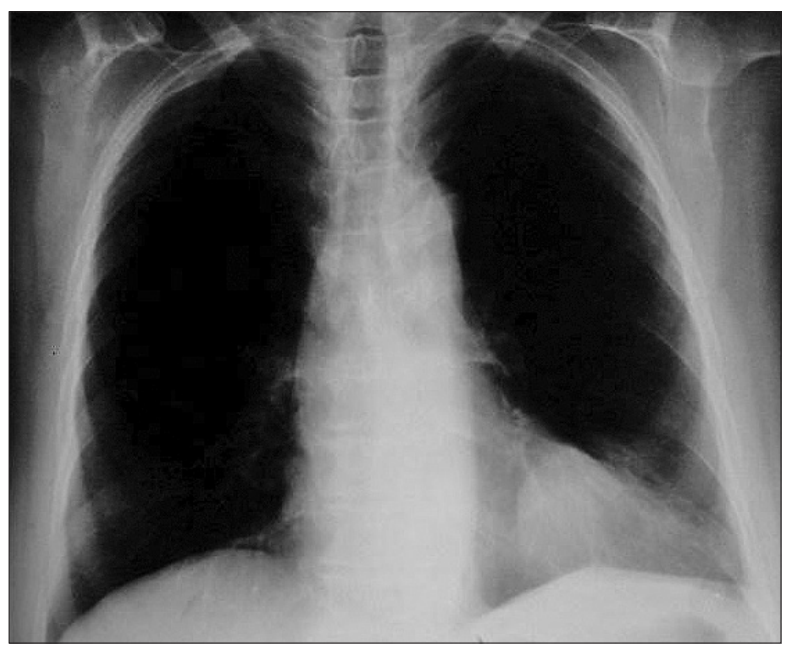

Fig. 1. - Chest radiograph shows heterogeneous density obliterating left costophrenic sinus. 


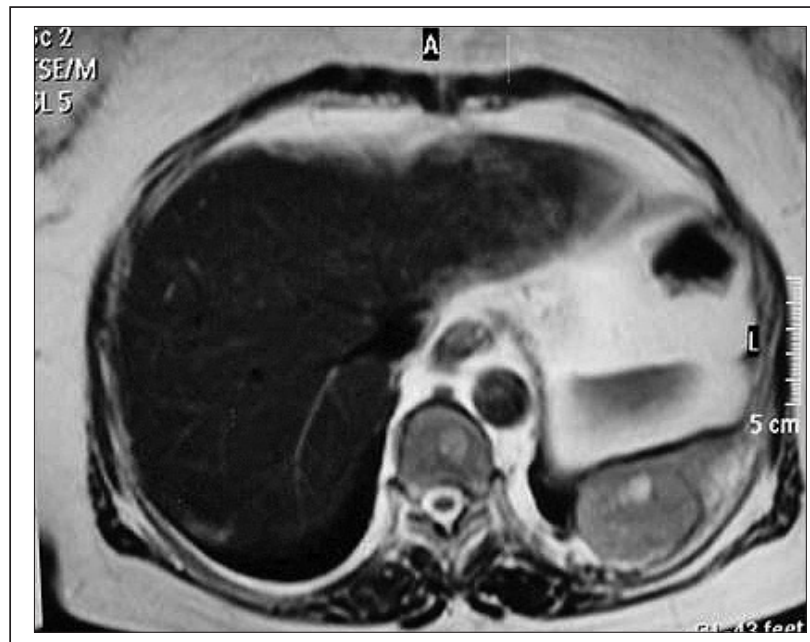

Fig. 2. - Magnetic resonance imaging shows 4 x $6 \mathrm{~cm}$ sized mass having calcification and necrosis in left hemithorax.

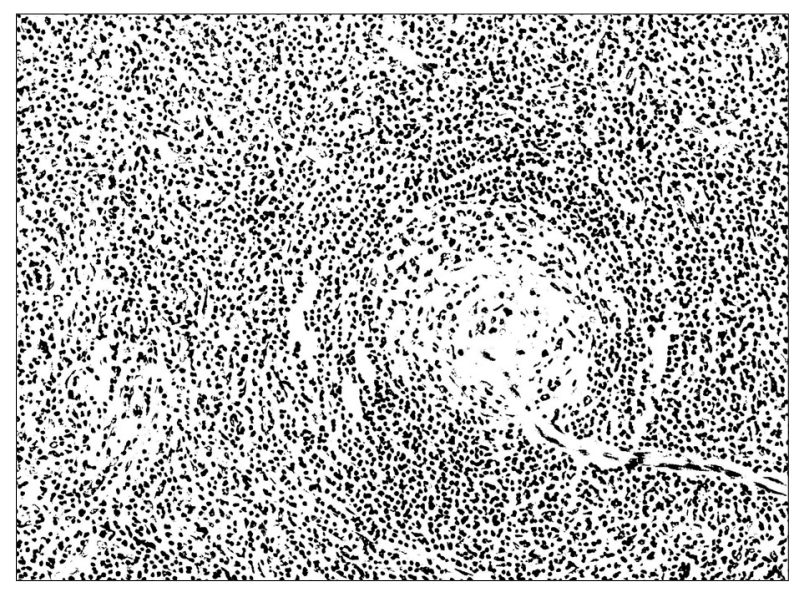

Fig. 3. - Histopathologic section shows typical features of hyalinevascular Castleman's disease with hyalinised vessels within germinal follicle formed by onion like sheets of lymphocytes and intervening prominent vascular stroma (H.E. X200).

years after resection, there was no apparent or recurrent disease on a computed tomography examination.

\section{Discussion}

Castleman's disease is an uncommon benign lymphoproliferative disorder [1]. It is also known as angiofollicular or giant lymph node hyperplasia [5]. The etiology of CD is unknown. It is reported that there is evidence suggesting the participation of viral infections such as human herpes virus 8 and Epstein-Barr virus [2]. The other hypothesis regarding pathogenesis of $\mathrm{CD}$ have been proposed including abnormal immunity, an immunodeficiency state, lymphoid hamartomatous hyperplasia, and, chronic low grade inflammatory process [4]. Although it has been identified at other anatomical sites, including the neck $(14 \%)$, abdomen (12\%), and axilla (4\%), the disease is most frequently $(70 \%)$ found in the thorax $[2,6]$. The pleura is an uncommon site for CD. It was found only in a few previously reported cases of pleural Castleman's disease in the literature $[1,6]$.

CD may occur at any age, but often in adults $[1,2]$. There is no sex predominance $[2,3]$. Three histological types have been described: hyaline vascular, plasma cell and mixed type [5]. The hyaline vascular type is more common ( $80 \%$ of cases) and is asymptomatic. The less frequent plasma cell type is often associated with systemic manifestations $[2,6]$. Respiratory symptoms are due to tracheobronchial compression such as cough, dyspnoea, chest pain, back pain and respiratory infections [3]. We report a older patient than previously reported cases. She described chest pain for 10 months. In our case, computed tomography of the chest revealed a mass lesion. In cases with pleural $\mathrm{CD}$, pleural mass $[1,3,6]$ and pleural effusion $[2$, 5] were described.

Based on biological behaviour, $\mathrm{CD}$ is categorised as unicentric form and multicentric form. Most of the former cases can be cured by surgical resection. Irradiation is treatment modality for unicentric type when surgery is not an option $[1,3,6$, 7]. Most of the latter do not benefit from surgical management $[4,6]$. Multicentric $C D$ requires systemic therapy which can include chemotherapy, antiviral therapy, steroids and the use of a humanised monoclonal antibody to IL-6 receptor $[2,7$, 8]. Our case had hyaline vascular type and was unicentric. She was treated with surgical resection. Four years after resection, there was no apparent or recurrent disease on a computed tomography examination.

In conclusion, pleural $\mathrm{CD}$ is a rare disorder. It can present as a pleural mass.

\section{References}

1. Mei-shan J, Li-mei QU, Yin-ping W. Castleman's disease of the pleura. J Chin Clin Med 2010; 5: 184-5.

2. Pinheiro VGF, Fernandes GH, Cezar LC, Alves NA, Menezes DB. Castleman's disease accompanied by pleural effusion. J Bras Pneumol 2008; 34: 626-30.

3. Rena O, Casadio C, Maggi G. Castleman's disease: unusual intrathoracic localization. Eur $J$ Cardiothorac Surg 2001; 19: 519-21.

4. Ko SF, Hsieh MJ, Ng SH, et al. Imaging spectrum of Castleman's disease. AJR 2004; 182: 769-75.

5. Hoor TT, Hewan-Lowe K, Miller JI, Moss M. A transitional variant of Castleman's disease presenting as a chylous pleural effusion. Chest 1999; 115: 285-8.

6. Ng SH, Ko SF, Lin JW, Wan YL, Hsieh MJ, Lee TY. Paracardiac pleural Castleman's disease: radiographic and MR findings. Br J Radiol 2004; 77: 433-5.

7. Dham A, Peterson BA. Castleman disease. Curr Opin Hematol 2007; 14: 354-9.

8. El-Hosta HE, Kurzrock R. Castleman's Disease: From Basic Mechanisms to Molecular Therapeutics. The Oncologist 2011; 16: 497-511. 